\title{
Metabolic and anthropometric changes in early breast cancer patients receiving adjuvant therapy
}

\author{
Grazia Arpino $^{1}$ (1) Carmine De Angelis ${ }^{1} \cdot$ Giuseppe Buono $^{1} \cdot$ Annamaria Colao $^{4}$. \\ Mario Giuliano $^{1} \cdot$ Simona Malgieri $^{1} \cdot$ Stefania Cicala $^{1} \cdot$ Michelino De Laurentiis $^{2}$. \\ Antonello Accurso $^{3}$ - Anna Crispo ${ }^{5}$ - Gennaro Limite ${ }^{3}$. Rossella Lauria ${ }^{1}$. \\ Bianca Maria Veneziani $^{6} \cdot$ Valeria Forestieri $^{1} \cdot$ Dario Bruzzese $^{7} \cdot$ Sabino De Placido $^{1}$
}

Received: 23 June 2015/ Accepted: 24 September 2015/Published online: 30 September 2015

(c) The Author(s) 2015. This article is published with open access at Springerlink.com

\begin{abstract}
Weight gain and metabolic changes have been related to survival of early breast cancer patients (EBC). "However, factors influencing metabolism post-diagnosis are not fully understood. We measured anthropometric [body mass index (BMI), body weight, waist and hip circumferences, and waist-to-hip ratio] and metabolic (levels of insulin, glucose, H1Ac, total, HDL, and LDL cholesterol, triglycerides, and the homeostasis model assessment score [HOMA]) parameters in 433 pre- and post-menopausal women with EBC at diagnosis and 3, 6, 9, 12, and 24 months thereafter. At diagnosis, compared with postmenopausal women, pre-menopausal patients were more likely to be leaner and to have a lower BMI, smaller waist
\end{abstract}

Electronic supplementary material The online version of this article (doi:10.1007/s10549-015-3586-x) contains supplementary material, which is available to authorized users.

Grazia Arpino

grazia.arpino@unina.it

1 Department of Clinical Medicine and Surgery, Oncology Division, University of Naples "Federico II" Medical School, Via S. Pansini 5, 80131 Naples, Italy

2 Department of Breast Medical Oncology, G. Pascale National Cancer Institute, Naples, Italy

3 Department of Surgery, University of Naples "Federico II" Medical School, Naples, Italy

4 Endocrinology Division, University of Naples "Federico II" Medical School, Naples, Italy

5 Division of Epidemiology, G. Pascale National Cancer Institute, Naples, Italy

6 Department of Clinical and Molecular Pathology, University of Naples "Federico II" Medical School, Naples, Italy

7 Department of Epidemiology, University of Naples "Federico II" Medical School, Naples, Italy and hip circumferences, and waist-to-hip ratio. They had also lower glucose, $\mathrm{HbAlc}$, and triglyceride levels and a lower HOMA score. Furthermore, they were more likely to have an estrogen- and/or progesterone-positive tumor and a higher proliferating breast cancer. During the first two postdiagnosis years, all women showed a significant increase of weight $(+0.72 \mathrm{~kg} /$ year, $P<0.001)$, waist circumference $(+1.53 \mathrm{~cm} /$ year, $P<0.001)$, and plasma levels of LDL cholesterol $(+5.4 \mathrm{mg} / \mathrm{dl}$ per year, $P=0.045)$ and triglycerides $(+10.73 \mathrm{mg} / \mathrm{dl}$ per year, $P=0.017)$. In patients receiving chemotherapy only, there was a significant increase in hip circumference $(+3.16 \mathrm{~cm} /$ year, $P<0.001)$ and plasma cholesterol levels $(+21.26 \mathrm{mg} / \mathrm{dl}$ per year, $P<0.001)$. We showed that weight, body fat distribution, and lipid profile changed in EBC patients receiving adjuvant therapy. These changes occurred during the first 2 years after diagnosis and were not specifically related to chemotherapy, menopausal status, or initial body weight.

Keywords Breast cancer - Body weight and composition · Glucose and lipid metabolism - Menopausal status - Adjuvant therapy

\section{Introduction}

Altered glucose metabolism and elevated body weight may affect breast cancer (BC) prognosis [1]. Plasma cholesterol levels may influence the risk of developing $\mathrm{BC}$ possibly because cholesterol is a precursor of steroid hormones [2, 3], and endogenous sex steroid hormones stimulate cell proliferation in BC [4]. Changes in metabolic parameters related to body weight and glucose and lipid metabolism have been observed after a BC diagnosis [5-9]. However, data on how, when, and for how long these changes occur 
are far from being conclusive. Most studies are based on retrospective chart review $[7,8,10,11]$, and body weight is the only metabolic parameter evaluated. In other instances, data were obtained during pretreatment and treatment but not at diagnosis [12]. Importantly, only two studies examined metabolic changes at prospectively established time points and beyond one year of follow-up [9, 13].

To address these limitations and to investigate factors potentially related to metabolic changes, we prospectively evaluated body weight and fat composition, and the glucose and lipid metabolism in women with early BC (EBC) before adjuvant therapy, during treatment, and 2 years after diagnosis.

\section{Patients and methods}

\section{Study population}

We enrolled women aged $\geq 18$ years with histologically confirmed BC treated with adjuvant chemotherapy and/or hormonal therapy at the University of Naples Federico II from July 2009 to October 2013. We excluded patients with a confirmed diagnosis of type I or type II diabetes based on laboratory data [21] and those taking medications that could affect lipids or insulin and glucose levels. This study was approved by the Ethics Committee of the University Federico II (IRB approval number 343/15), and the participants provided written informed consent to participate.

\section{Data retrieval}

Demographics, tumor stage and size $(\mathrm{T})$, nodal status $(\mathrm{N})$, estrogen receptor (ER), grading $(\mathrm{G})$ progesterone receptor (PR) and HER2/neu status, and tumor proliferation measured by ki67 labeling were collected. Body weight, height, and waist and hip circumferences were measured before treatment (baseline) and 3, 6, 9, 12, and 24 months thereafter. Waist and hip circumferences were measured as previously described [14]. Body mass index (BMI) was calculated as weight divided by height squared, and the waist-to-hip ratio was calculated as waist circumference divided by hip circumference.

\section{Laboratory assays}

Fasting glucose $(\mathrm{mg} / \mathrm{dl})$, serum insulin $(\mu \mathrm{UI} / \mathrm{ml})$, glycosylated hemoglobin (HbA1c, \%), total, HDL, and LDL cholesterol $(\mathrm{mg} / \mathrm{dl})$, and triglycerides $(\mathrm{mg} / \mathrm{dl})$ were measured on venous blood collected at the time of diagnosis, before cancer therapy (baseline). The homeostasis model assessment (HOMA) index was calculated as glucose (mg/dl) multiplied by insulin $(\mu \mathrm{UI} / \mathrm{ml})$ divided by 40 . Blood samples were collected in standardized conditions after overnight fasting between $7 \mathrm{am}$ and $10 \mathrm{am}$. All measurements were repeated $3,6,9,12$, and 24 months after baseline measurements.

\section{Data analyses}

Analyses were conducted in R version 3.0.1. Quantitative variables were summarized with mean \pm standard deviation (SD); frequencies (percentage) were used for qualitative variables. Anthropometric parameters (post-diagnosis body weight, BMI, waist and hip circumferences, and waist-to-hip ratio), blood metabolic profile (blood glucose, serum insulin, HbA1c, total cholesterol, HDL cholesterol, LDL cholesterol, and triglycerides), and tumor characteristics (T, N, G, Ki67, ER, PgR, HER2, and treatment) were compared at baseline between pre-menopausal and postmenopausal patients with Student's $t$ test and Chi-square test for numerical and categorical variables, respectively. Non-parametric Spearman rho was used to assess correlations among primary tumor characteristics and baseline anthropometric and metabolic variables. To determine the longitudinal variation of anthropometric and metabolic parameters, we used a set of linear mixed models with patient-level random effect for the intercept and with the fixed effect of time coded continuously as the number of years from diagnosis. The following fixed effects were included: hormone receptor (HR) status, adjuvant treatment, menopause status, T, N, HER-2, age, and BMI. In each analysis, the significance of the interaction between type of treatment and time was tested and, if significant, the corresponding term was added to the model. The results of linear mixed models are expressed as adjusted yearly change in the corresponding outcome variable with $95 \%$ CI. A two-sided $P<0.05$ was considered statistically significant.

\section{Results}

\section{Demographic, clinical, and biological characteristics}

A total of 433 EBC patients (175 pre-menopausal and 258 post-menopausal) were enrolled in the study. The patients' baseline clinical and metabolic characteristics stratified for menopausal status are summarized in Table 1. At diagnosis, compared to post-menopausal patients, pre-menopausal women were more likely to be leaner (mean body weight: $67.9 \pm 13.2$ vs. $71.6 \pm 13.9 \mathrm{~kg} ; P<0.001)$, to have a lower BMI (26.3 \pm 5 vs. $\left.29.4 \pm 5.8 \mathrm{~kg} / \mathrm{m}^{2} ; P<0.001\right)$, and to have a smaller waist circumference $(87.3 \pm 12.5 \mathrm{~cm}$ vs. $94.8 \pm 14.7 \mathrm{~cm}, \quad P<0.001), \quad$ hip circumference 
Table 1 Baseline patient clinical and metabolic characteristics stratified by menopausal status

\begin{tabular}{lccr}
\hline & Pre-menopause $(n=173)$ & Post-menopause $(n=258)$ & $p$ value \\
\hline Age & $42.5 \pm 5.5$ & $61.1 \pm 6.8$ & $<0.001$ \\
Body weight & $67.9 \pm 13.2$ & $71.6 \pm 13.9$ & 0.004 \\
Body mass index & $26.3 \pm 5$ & $29.4 \pm 5.8$ & $<0.001$ \\
Waist circumference & $87.3 \pm 12.5$ & $94.8 \pm 14.7$ & $<0.001$ \\
Hip circumference & $100.6 \pm 10.8$ & $106.2 \pm 11.7$ & $<0.001$ \\
Waist-to-hip ratio & $0.87 \pm 0.07$ & $0.89 \pm 0.09$ & $<0.001$ \\
Glucose & $92.22 \pm 14.88$ & $104.78 \pm 33.09$ & $<0.001$ \\
Insulin & $11.56 \pm 13.89$ & $12.78 \pm 13.61$ & 0.097 \\
HOMA index & $2.46 \pm 3.12$ & $3.29 \pm 3.37$ & 0.006 \\
HbA1c & $5.68 \pm 2.62$ & $6.16 \pm 3.45$ & 0.001 \\
Total cholesterol & $200.89 \pm 38.57$ & $208.22 \pm 40.65$ & 0.081 \\
HDL cholesterol & $61.26 \pm 16.82$ & $60.01 \pm 18.46$ & 0.388 \\
LDL cholesterol & $119.64 \pm 37.07$ & $126.84 \pm 39.37$ & 0.393 \\
Triglycerides & $87.89 \pm 42.46$ & $123.1 \pm 68.45$ & $<0.001$ \\
\hline
\end{tabular}

$(100.6 \pm 10.8 \mathrm{~cm}$ vs. $106.2 \pm 11.7 \mathrm{~cm}, P<0.001)$, and waist-to-hip ratio (0.87 \pm 0.07 vs. $0.89 \pm 0.09, P<0.001)$. Unsurprisingly, post-menopausal patients were more likely than pre-menopausal patients to have a lower glucose level $(92.22 \pm 14.88 \mathrm{mg} / \mathrm{dl} \quad$ vs. $\quad 104.78 \pm 33.09 \mathrm{mg} / \mathrm{dl}$ : $P<0.001)$, lower HOMA index $(2.46 \pm 3.12$ vs $3.29 \pm 3.37, \mathrm{p}=0.006)$, lower HbA1c level $(5.68 \pm 2.62$ vs. $6.16 \pm 3.45 ; P=0001)$, and a lower triglyceride level $(87.89 \pm 42.46 \mathrm{mg} / \mathrm{dl} \quad$ vs. $\quad 123.1 \pm 68.45 \mathrm{mg} / \mathrm{dl}$; $P<0.001)$. Insulin, cholesterol, HDL, and LDL levels were unrelated to menopausal status.

Table 2 shows the baseline tumor characteristics stratified for menopausal status in our patients. Pre-menopausal women were more likely than post-menopausal women to have a tumor that was ER positive (87.9 vs. $79.8 \%$; $P=0.036)$, PR positive ( 85.5 vs. $76.7 \% ; P=0.026)$, and highly proliferating (mean ki67 $32.2 \pm 21.4$ vs. $27.7 \pm 19.9 ; P=0.025)$. Nodal status, $G$, and HER 2 status were not related to menopausal status.

Adjuvant therapy differed significantly according to menopausal status $(P=0.016)$. In detail, pre-menopausal patients were more frequently treated with chemotherapy followed by endocrine therapy (63.6 vs. $49.6 \%$ ) and less frequently by chemotherapy alone (14.4 vs. $21.3 \%$ ) or hormonal therapy alone (22.0 vs. $29.1 \%)$. Most patients (76\%), receiving chemotherapy alone, received combined sequential treatment with anthracycline and cyclophosphamide for 4 cycles and weekly paclitaxel for 12 weeks. All HER2-positive patients received trastuzumab for 18 consecutive cycles. Among post-menopausal patients, 22 $(10.8 \%), 82(40.4 \%), 35(17.3 \%)$, and $24(11.8 \%)$ received 5 years of anastrozole, letrozole, exemestane, and tamoxifen, and $13(6.4 \%), 17(8.4 \%)$, and $10(4.9 \%)$ received tamoxifen for 2 years followed by anastrozole, letrozole, and exemestane, respectively.

\section{Mean change per year of anthropometric and metabolic variables after adjuvant treatment}

To characterize the pattern of anthropometric and metabolic changes occurring during the 24 months after diagnosis, we used linear mixed models after removing the effect of the following baseline variables: HR status, systemic adjuvant treatment, menopause status, tumor size, nodal status, HER-2, age, and BMI (Table 3). Over a median follow-up of 14 months (range: 6-24 months), there was a statistically significant increase in weight $(+0.72 \mathrm{~kg} /$ year, $95 \%$ CI $0.32-1.11 ; P<0.001)$ and waist circumference $(+1.53 \mathrm{~cm} /$ year, $95 \%$ CI $0.85-2.22$; $P<0.001)$ in the overall population. In modeling hip circumference, there was a significant interaction effect between time and treatment ( $F$ for interaction 3.723, $P=0.025)$. In particular, only in patients receiving chemotherapy alone there was a statistically significant increase in hip circumference $(+3.16 \mathrm{~cm} /$ year, $95 \%$ CI 1.60-4.73; $P<0.001)$. Among metabolic variables, there were statistically significant increases in plasma levels of LDL cholesterol $(+5.4 \mathrm{mg} / \mathrm{dl}$ per year, $95 \%$ CI 0.12-10.68; $P=0.045)$ and triglycerides $(+10.73 \mathrm{mg} / \mathrm{dl}$ per year, $95 \%$ CI 1.95-19.51; $P=0.017$ ) in all patients. Cholesterol level was significantly increased in patients receiving chemotherapy alone $(+21.26 \mathrm{mg} / \mathrm{dl}$ per year, $95 \%$ CI 10.18-32.35; $P=<0.001)$ but not in the other subgroups ( $F$ for interaction $4.03, P=0.019$ ). Lastly, no statistically significant changes in glucose metabolism markers, namely glucose and insulin levels and $\mathrm{HbA} 1 \mathrm{C}$ protein, were observed. Among post-menopausal patients, women receiving hormonal therapy did not experience a statistically significant change in weight, waist or hip circumferences, LDL cholesterol, triglycerides, and glucose blood levels when compared to patients receiving 
Table 2 Baseline tumor characteristics stratified by menopausal status

\begin{tabular}{|c|c|c|c|}
\hline & $\begin{array}{l}\text { Pre- } \\
\text { menopause } \\
(n=173)\end{array}$ & $\begin{array}{l}\text { Post- } \\
\text { menopause } \\
(n=258)\end{array}$ & $P$ value \\
\hline \multicolumn{4}{|l|}{ Tumor size } \\
\hline Mean $\pm \mathrm{SD}$ & $21.6 \pm 14.4$ & $20.7 \pm 11.8$ & 0.862 \\
\hline$<2 \mathrm{~cm}$ & $93(54.4)$ & $136(52.9)$ & 0.766 \\
\hline$\geq 2 \mathrm{~cm}$ & $78(45.6)$ & $121(47.1)$ & \\
\hline Nodal status, $n(\%)$ & & & 0.073 \\
\hline Negative & $87(50.9)$ & $131(52.4)$ & \\
\hline Positive & $84(49.1)$ & $119(47.6)$ & \\
\hline Grading, $n(\%)$ & & & 0.745 \\
\hline G1 & $7(4.1)$ & $13(5.1)$ & \\
\hline $\mathrm{G} 2$ & $57(33.1)$ & $90(35.6)$ & \\
\hline G3 & $108(62.8)$ & $150(59.3)$ & \\
\hline \multicolumn{4}{|l|}{ Ki67 } \\
\hline Mean \pm SD & $32.2 \pm 21.4$ & $27.7 \pm 19.9$ & 0.025 \\
\hline$\leq 15 \%$ & $55(33.1)$ & $106(42.7)$ & 0.062 \\
\hline$>15 \%$ & $111(66.9)$ & $142(57.3)$ & \\
\hline ER & & & 0.036 \\
\hline Negative & $21(12.1)$ & $52(20.2)$ & \\
\hline Positive & $152(87.9)$ & $206(79.8)$ & \\
\hline $\mathrm{PgR}$ & & & 0.026 \\
\hline Negative & $25(14.5)$ & $60(23.3)$ & \\
\hline Positive & $147(85.5)$ & $198(76.7)$ & \\
\hline HER2 & & & 0.700 \\
\hline Negative & $140(81.4)$ & $214(82.9)$ & \\
\hline Positive & $32(18.6)$ & $44(17.1)$ & \\
\hline Treatment, $n(\%)$ & & & 0.016 \\
\hline Chemotherapy only & $25(14.4)$ & $55(21.3)$ & \\
\hline Endocrine therapy only & $38(22.0)$ & $75(29.1)$ & \\
\hline $\begin{array}{l}\text { Chemotherapy followed } \\
\text { by endocrine therapy }\end{array}$ & $110(63.6)$ & $128(49.6)$ & \\
\hline
\end{tabular}

$E R$ estrogen receptor, $P g R$ progesterone receptor

chemotherapy only (data not shown). Importantly, in the same patients' group, there was not a statistically significant change in the anthropometric or metabolic parameters included in the study according to the type of hormonal therapy (data not shown).

\section{Discussion}

In this study, we assessed metabolic changes occurring after BC diagnosis and explored factors potentially implicated in these variations. Our EBC patients gained weight during the first 2 years after diagnosis, with an increase of $0.72 \mathrm{~kg} /$ year regardless of menopausal status, type of adjuvant therapy delivered, body weight, or BMI at baseline. Consistent with our findings, most previous studies
Table 3 Mean change per year of metabolic variables adjusted for hormone receptor status, systemic adjuvant treatment, menopause, tumor dimension, nodal status, HER 2, age, and body mass index

\begin{tabular}{lllr}
\hline & Mean change/year & $95 \%$ CI & $P$ value \\
\hline Body weight & +0.72 & 0.32 to 1.11 & $<0.001$ \\
Waist circumference & +1.53 & 0.85 to 2.22 & $<0.001$ \\
Hip circumference & & & \\
CT + OT & +0.82 & -0.06 to 1.70 & 0.069 \\
CT & +3.16 & 1.60 to 4.73 & $<0.001$ \\
OT & +0.72 & -0.46 to 1.90 & 0.233 \\
Glucose & -0.83 & -3.52 to 1.86 & 0.545 \\
Insulin & -0.55 & -2.30 to 1.19 & 0.531 \\
HbA1c & -0.22 & -0.63 to 0.20 & 0.301 \\
Total cholesterol & & & \\
CT + OT & +3.82 & -2.40 to 10.03 & 0.228 \\
CT & +21.26 & 10.18 to 32.35 & $<0.001$ \\
OT & +2.07 & -9.97 to 14.11 & 0.735 \\
HDL cholesterol & -1.93 & -5.39 to 1.53 & 0.272 \\
LDL cholesterol & +5.40 & 0.12 to 10.68 & 0.045 \\
Triglycerides & +10.73 & 1.95 to 19.51 & 0.017 \\
\hline CT chemotherapy & OT & &
\end{tabular}

$C T$ chemotherapy, $O T$ endocrine therapy

reported weight increase ranging from few grams to several kgs (see Table S1, supplementary material) $[5,12,13,15-$ 23] after BC diagnosis. Some authors have suggested that menopausal status influences the extent of weight gained during adjuvant therapy. Two studies reported that weight gain was more pronounced in pre-menopausal women than in post-menopausal women [24, 25], thereby implicating ovarian failure and menopause onset in weight variation [15]. However, this finding is not confirmed by other studies [10, 24, 26, 27]. We did not detect any difference in the extent of weight increase in relation to menopausal status or to age at diagnosis. The median age of our premenopausal patients was 42 years, and it is possible that the impact of treatment-related amenorrhea (due to chemotherapy or ovarian function suppression) on body weight may have been masked by a pretreatment perimenopausal hormone status in most of them. In a much younger cohort of patients, the impact of drug-related amenorrhea might have been more pronounced.

In previous studies $[18,19,28]$, women gained more weight with chemotherapy than with hormonal therapy or radiotherapy. All our patients received adjuvant systemic treatment and, importantly, weight gain was unrelated to the type of systemic therapy delivered. The most frequent hormonal agent given in earlier studies was tamoxifen [18, 19, 28]. Aromatase inhibitors for post-menopausal and ovary suppression in addition to tamoxifen for pre-menopausal women were the most frequently used hormonal therapies in our patients (data not shown). We cannot 
exclude that hormonal agents that have completely different toxicity profiles affect differently the patient's metabolism and energy balance.

Our data show that weight increase is also associated to changes of fat body composition, namely an increase of waist circumference and hip circumference, especially in patients who received chemotherapy. Waist and hip circumference and waist-to-hip ratio are additional measures of body fat distribution and provide an index of both subcutaneous and intra-abdominal adipose tissue [14]. Several studies reported a significant increase in fat mass and a change in body fat distribution during chemotherapy [29-32]. Interestingly, chemotherapy-induced weight gain and changes in body composition seem to occur in specific body zones, namely the legs, trunk, and arms, and lean body mass losses affect predominantly the legs and lower trunk [28, 33].

Our study confirms the occurrence of body composition changes during and after adjuvant treatment, especially in patients treated with chemotherapy alone [15, 29-32]. Of note, our patients who received chemotherapy alone were mostly treated with longer-lasting regimens containing taxane and anthracyclines. It was suggested that chemotherapy, particularly anthracyclines, may impair muscle function by reducing mitochondrial respiratory efficiency and cytosolic adenosine triphosphate content [34], which can accentuate fatigue and inactivity, and induce an increase of fat deposition in specific body areas [34].

To our knowledge, ours is the first study to evaluate whether serum metabolic biomarkers are compromised by adjuvant treatment received after a diagnosis of BC. In our patients, LDL cholesterol and triglyceride levels significantly increased during the 2 years after treatment irrespective of the type of therapy delivered. Consequently, this effect could be due to diet or lifestyle changes after BC diagnosis rather than to a side-effect of treatment. In patients treated with chemotherapy only, there was a greater increase of total cholesterol, probably due to the extensive use of anthracyclines in this subgroup. Adjuvant therapy did not seem to affect glucose metabolism in our patients.

A limitation of our study is the lack of a control arm constituted by women receiving local therapy alone. However, our analysis reflects current clinical practice where it is highly unlikely for an EBC patient not to receive systemic adjuvant therapy after local therapy, and therefore our results are applicable to most patients. Furthermore, a case-control study specifically addressing this question is not realistic and, in any event, may not yield information helpful for daily clinical practice. Furthermore, we did not analyze other potential indicators of weight gain, namely energy expenditure, dietary factors, change in menopausal status or in sexual hormonal status during and after systemic chemotherapy, and psychological factors. Our cohort is relatively homogeneous in terms of race, education, and social status (most patients were well educated and employed or retired); consequently, our results may not be generalized to all EBC survivors in different geographic areas.

In summary, we observed important alterations of metabolism (increase in body weight, waist and hip circumferences, LDL, triglyceride, and total cholesterol serum levels) in our patients receiving adjuvant therapy. These alterations, regardless of the specific cause, persisted up to 24 months after diagnosis and, as such, may be responsible for the reduced survival of EBC patients. Patients should be counseled about the risk of weight gain and of an altered lipid profile after a BC diagnosis, and should be aware that adjuvant hormonal therapy alone may not necessarily prevent these metabolic alterations. Preventive measures to reduce the risk of increasing weight and to reduce or maintain a healthy lipid profile should be offered to women who decide to undergo adjuvant systemic treatment after a diagnosis of EBC and local treatment.

Acknowledgments We thank Jean Ann Gilder (Scientific Communication srl., Naples, Italy) for editing the manuscript.

Funding This work was supported by the grant PRIN [Grant number 2010NFEB9L].

\section{Compliance with ethical standards}

Conflict of interest The authors declare that they have no conflict of interest.

Ethical approval All procedures performed in studies involving human participants were in accordance with the ethical standards of the institutional and/or national research committee and with the 1964 Helsinki declaration and its later amendments or comparable ethical standards.

Open Access This article is distributed under the terms of the Creative Commons Attribution-NonCommercial 4.0 International License (http://creativecommons.org/licenses/by-nc/4.0/), which permits any noncommercial use, distribution, and reproduction in any medium, provided you give appropriate credit to the original author(s) and the source, provide a link to the Creative Commons license, and indicate if changes were made.

\section{References}

1. Goodwin PJ, Ennis M, Pritchard KI, Trudeau ME, Koo J, Taylor SK, Hood N (2012) Insulin- and obesity-related variables in early-stage breast cancer: correlations and time course of prognostic associations. J Clin Oncol 30(2):164-171. doi:10.1200/ JCO.2011.36.2723 
2. Vatten LJ, Foss OP (1990) Total serum cholesterol and triglycerides and risk of breast cancer: a prospective study of 24,329 Norwegian women. Cancer Res 50(8):2341-2346

3. Smethurst M, Basu TK, Williams DC (1975) Levels of cholesterol, 11-hydroxycorticosteroids and progesterone in plasma from postmenopausal women with breast cancer. Eur $\mathbf{J}$ Cancer 11(10):751-755

4. Key T, Appleby P, Barnes I, Reeves G, Endogenous H, Breast Cancer Collaborative G (2002) Endogenous sex hormones and breast cancer in postmenopausal women: reanalysis of nine prospective studies. J Natl Cancer Inst 94(8):606-616

5. Camoriano JK, Loprinzi CL, Ingle JN, Therneau TM, Krook JE, Veeder MH (1990) Weight change in women treated with adjuvant therapy or observed following mastectomy for node-positive breast cancer. J Clin Oncol 8(8):1327-1334

6. Chlebowski RT, Weiner JM, Reynolds R, Luce J, Bulcavage L, Bateman JR (1986) Long-term survival following relapse after 5-FU but not CMF adjuvant breast cancer therapy. Breast Cancer Res Treat 7(1):23-30

7. Goodwin PJ, Panzarella T, Boyd NF (1988) Weight gain in women with localized breast cancer-a descriptive study. Breast Cancer Res Treat 11(1):59-66

8. Heasman KZ, Sutherland HJ, Campbell JA, Elhakim T, Boyd NF (1985) Weight gain during adjuvant chemotherapy for breast cancer. Breast Cancer Res Treat 5(2):195-200

9. Levine EG, Raczynski JM, Carpenter JT (1991) Weight gain with breast cancer adjuvant treatment. Cancer 67(7):1954-1959

10. Rock CL, Flatt SW, Newman V, Caan BJ, Haan MN, Stefanick ML, Faerber S, Pierce JP (1999) Factors associated with weight gain in women after diagnosis of breast cancer. Women's Healthy Eating and Living Study Group. J Am Diet Assoc 99(10):1212-1221

11. Costa LJ, Varella PC, del Giglio A (2002) Weight changes during chemotherapy for breast cancer. Sao Paulo Med J 120(4):113-117

12. Vagenas D, DiSipio T, Battistutta D, Demark-Wahnefried W, Rye S, Bashford J, Pyke C, Saunders C, Hayes SC (2015) Weight and weight change following breast cancer: evidence from a prospective, population-based, breast cancer cohort study. BMC Cancer 15(1):28. doi:10.1186/s12885-015-1026-2

13. Rodrigues Dos Santos C, Fonseca I, Dias S, Mendes de Almeida JC (2014) Plasma level of LDL-cholesterol at diagnosis is a predictor factor of breast tumor progression. BMC Cancer 14:132. doi:10.1186/1471-2407-14-132

14. Bjorntorp P (1987) Fat cell distribution and metabolism. Ann N Y Acad Sci 499:66-72

15. Goodwin PJ, Ennis M, Pritchard KI, McCready D, Koo J, Sidlofsky S, Trudeau M, Hood N, Redwood S (1999) Adjuvant treatment and onset of menopause predict weight gain after breast cancer diagnosis. J Clin Oncol 17(1):120-129

16. Kroenke CH, Chen WY, Rosner B, Holmes MD (2005) Weight, weight gain, and survival after breast cancer diagnosis. J Clin Oncol 23(7):1370-1378. doi:10.1200/JCO.2005.01.079

17. Nichols HB, Trentham-Dietz A, Egan KM et al (2009) Body mass index before and after breast cancer diagnosis: associations with all-cause, breast cancer, and cardiovascular disease mortality. Cancer Epidemiol Biomarker Prev 18: 1403-1409

18. Heideman WH, Russell NS, Gundy C, Rookus MA, Voskuil DW (2009) The frequency, magnitude and timing of post-diagnosis body weight gain in Dutch breast cancer survivors. Eur J Cancer 45(1):119-126. doi:10.1016/j.ejca.2008.09.003

19. Saquib N, Flatt SW, Natarajan L, Thomson CA, Bardwell WA, Caan B, Rock CL, Pierce JP (2007) Weight gain and recovery of pre-cancer weight after breast cancer treatments: evidence from the women's healthy eating and living (WHEL) study. Breast
Cancer Res Treat 105(2):177-186. doi:10.1007/s10549-0069442-2

20. Tredan O, Bajard A, Meunier A, Roux P, Fiorletta I, Gargi T, Bachelot T, Guastalla JP, Lallemand Y, Faure C, Perol D, Bachmann P (2010) Body weight change in women receiving adjuvant chemotherapy for breast cancer: a French prospective study. Clin Nutr 29(2):187-191. doi:10.1016/j.clnu.2009.08.003

21. Gu K, Chen X, Zheng Y, Chen Z, Zheng W, Lu W, Shu XO (2010) Weight change patterns among breast cancer survivors: results from the Shanghai breast cancer survival study. Cancer Causes Control 21(4):621-629. doi:10.1007/s10552-009-9491-z

22. Thivat E, Therondel S, Lapirot O, Abrial C, Gimbergues P, Gadea E, Planchat E, Kwiatkowski F, Mouret-Reynier MA, Chollet P, Durando X (2010) Weight change during chemotherapy changes the prognosis in non metastatic breast cancer for the worse. BMC Cancer 10:648. doi:10.1186/1471-2407-10-648

23. Xiaoli Chen WL, Kai G, Chen Zhi, Zheng Ying, Zheng Wei, Shu Xiao Ou (2011) Weight change and its correlates among breast cancer survivors. Nutr Cancer 63(4):538-548. doi:10.1080/ 01635581.2011 .539316

24. Caan BJ, Kwan ML, Hartzell G, Castillo A, Slattery ML, Sternfeld B, Weltzien E (2008) Pre-diagnosis body mass index, post-diagnosis weight change, and prognosis among women with early stage breast cancer. Cancer Causes Control 19(10):1319-1328. doi:10.1007/s10552-008-9203-0

25. Demark-Wahnefried W, Winer EP, Rimer BK (1993) Why women gain weight with adjuvant chemotherapy for breast cancer. J Clin Oncol 11(7):1418-1429

26. Irwin ML, McTiernan A, Baumgartner RN, Baumgartner KB, Bernstein L, Gilliland FD, Ballard-Barbash R (2005) Changes in body fat and weight after a breast cancer diagnosis: influence of demographic, prognostic, and lifestyle factors. J Clin Oncology 23(4):774-782. doi:10.1200/JCO.2005.04.036

27. Han HS, Lee KW, Kim JH, Kim SW, Kim IA, Oh DY, Im SA, Bang SM, Lee JS (2009) Weight changes after adjuvant treatment in Korean women with early breast cancer. Breast Cancer Res Treat 114(1):147-153. doi:10.1007/s10549-008-9984-6

28. Demark-Wahnefried W, Peterson BL, Winer EP, Marks L, Aziz N, Marcom PK, Blackwell K, Rimer BK (2001) Changes in weight, body composition, and factors influencing energy balance among premenopausal breast cancer patients receiving adjuvant chemotherapy. J Clin Oncol 19(9):2381-2389

29. Harvie MN, Campbell IT, Baildam A, Howell A (2004) Energy balance in early breast cancer patients receiving adjuvant chemotherapy. Breast Cancer Res Treat 83(3):201-210. doi:10. 1023/B:BREA.0000014037.48744.fa

30. Aslani A, Smith RC, Allen BJ, Pavlakis N, Levi JA (1999) Changes in body composition during breast cancer chemotherapy with the CMF-regimen. Breast Cancer Res Treat 57(3):285-290

31. Freedman RJ, Aziz N, Albanes D, Hartman T, Danforth D, Hill S, Sebring N, Reynolds JC, Yanovski JA (2004) Weight and body composition changes during and after adjuvant chemotherapy in women with breast cancer. J Clin Endocrinol Metabol 89(5):2248-2253. doi:10.1210/jc.2003-031874

32. Campbell KL, Lane K, Martin AD, Gelmon KA, McKenzie DC (2007) Resting energy expenditure and body mass changes in women during adjuvant chemotherapy for breast cancer. Cancer Nurs 30(2):95-100. doi:10.1097/01.NCC.0000265004.64440.5f

33. Kutynec CL, McCargar L, Barr SI, Hislop TG (1999) Energy balance in women with breast cancer during adjuvant treatment. J Am Diet Assoc 99(10):1222-1227

34. Hiona A, Lee AS, Nagendran J, Xie X, Connolly AJ, Robbins RC, Wu JC (2011) Pretreatment with angiotensin-converting enzyme inhibitor improves doxorubicin-induced cardiomyopathy via preservation of mitochondrial function. J Thoracic Cardiovas Surg 142(2):396-403 